\title{
Multiculturalismo, globalização e formação de educadores: desafios para a educação ambiental
}

\section{Multiculturalism, Globalization and Educators Development: Challenges for Environmental Education}

\author{
Angélica Gois MORALES* \\ José Edmilson SOUZA-LIMA** \\ Maria do Rosário KNECHTEL ${ }^{* * *}$ \\ Sônia Maria Marchiorato CARNEIRO**** \\ Valdir NOGUEIRA*****
}

\begin{abstract}
RESUMO
O presente artigo é resultado de uma pesquisa teórico-bibliográfica que enfoca a Educação Ambiental sob uma perspectiva multicultural. Para tanto, no contexto do debate sobre a globalização, coloca-se a relação entre multiculturalismo e Educação Ambiental, considerando-se a urgência de uma reflexão entre educadores, pesquisadores, a universidade e outros segmentos sociais - como organizações governamentais e não governamentais. Parte-se do pressuposto de que a Educação, enquanto prática social promotora da cidadania democrática, deve orientar-se por finalidades multiculturais, corroborando a interculturalidade. A Educação Ambiental é uma das dimensões da Educação que pode contribuir, significativamente, para o avanço das práticas socioculturais. Tal perspectiva implica pensar as estratégias de formação de educadores, na linha de uma visão interdisciplinar e complexa de mundo, no contexto da educação ambiental sob a perspectiva multicultural.
\end{abstract}

Palavras-chave: educação ambiental; multiculturalismo; formação de educadores.

\begin{abstract}
This article results from a theoretic-bibliographical research that focuses on Environmental Education under a multicultural perspective. For that purpose, the discussion about globalization and the relation
\end{abstract}

\footnotetext{
" Doutora em Meio Ambiente e Desenvolvimento (UFPR). Professora do Departamento de Biologia Geral e do Programa de Pós-Graduação em Educação da Universidade Estadual de Ponta Grossa (UEPG). Email: angelicagoismorales@ig.com.br

** Doutor em Meio Ambiente e Desenvolvimento (UFPR). Professor do Mestrado em Organizações e Desenvolvimento do Centro Universitário Franciscano do Paraná (UNIFAE). Email: edmilson@ufpr.br

"** Doutora em Sociologia da Educação Ambiental (UFS). Professora Sênior do Doutorado em Meio Ambiente e Desenvolvimento da Universidade Federal do Paraná (UFPR). Email: mknechtel10@gmail.com

**** Doutora em Meio Ambiente e Desenvolvimento (UFPR). Professora Sênior do Programa de Pós-Graduação em Educação da Universidade Federal do Paraná (UFPR). Email: sonmarc@brturbo.com.br

***** Doutor em Educação (UFPR). Professor do Departamento de Metodologia de Ensino do Centro de Educação da Universidade Federal de Santa Maria (UFSM). Email: nogueira.ufsm@hotmail.com
} 
between Multiculturalism and Environmental Education takes into consideration the urgency of the matter among educators, researchers, the university and other social sectors such as governmental and non-governmental organizations. It is assumed that Education as a social practice and promoter of the democratic citizenship should be guided by multicultural purposes, corroborating inter-cultural practices. The Environmental Education is one of the Educational dimensions that can contribute significantly to the advance of socio-cultural practices. Such perspective leads to thinking about and constructing educational strategies in order to professionally develop and endow educators with an interdisciplinary and complex view of the world, within the context of environmental education on a multicultural perspective.

Key-words: environmental education; multiculturalism; instruction and development of educators.

\section{Introdução}

Um desafio político do século XXI será a escolha entre duas opções possíveis: ou uma política de destruição das identidades culturais pela exterminação, a exclusão ou a assimilação - ou a instituição de sociedades políticas multiculturais nas quais as relações de diálogo produzirão mestiçagem cultural. Este desafio é o da fraternidade cívica (LAPIERRE ${ }^{1}$, apud SANTOS, 2005).

O presente artigo está relacionado à necessidade de se apresentar, no bojo do debate sobre a globalização, a questão do multiculturalismo e a Educação Ambiental não como campos isolados e distantes, mas como dois âmbitos de coexistência das racionalidades socioculturais. $\mathrm{O}$ encontro desses dois domínios emerge inicialmente como um manifesto contra toda e qualquer materialização de etnocentrismo, mas, além disso, possibilita a reflexão e a (re)construção de novas perspectivas para a Educação Ambiental.

Nessa linha, a pesquisa em foco, de cunho teórico-bibliográfico, tem como objetivo principal contribuir para aproximar a Educação Ambiental do multiculturalismo no contexto da globalização, corroborando o desenvolvimento teórico-metodológico da EA, em vista da formação de educadores na realidade brasileira.

$\mathrm{O}$ artigo está estruturado em três partes principais e respectivos subitens. Na primeira, discute-se o fenômeno do multiculturalismo no contexto da globalização; na sequência, o multiculturalismo e Educação Ambiental; na segunda parte, a formação de educadores e a interdisciplinaridade como prática pedagógica fundamental; e, na terceira, a universidade e a formação de educadores ambientais, contemplando trajetórias históricas e reflexões nesse nível de ensino e perspectivas de avanços para uma abordagem multicultural.

\section{Educação ambiental e multiculturalismo no contexto da globalização}

As ponderações iniciais remetem, neste momento, à explicitação e ao entendimento do fenômeno multicultural no processo da globalização e suas implicações em vista da Educação Ambiental.

\section{Multiculturalismo e globalização}

A globalização, determinada pelas ideologias neoliberais econômicas e políticas, tem uma dimensão cultural substantiva, via mercado de produtos culturais (SACRISTÁN, 2002) que impõe uma globalização cultural - especialmente pelas tecnologias de informação e comunicação-transporte, afetando os modos de pensar e viver dos indivíduos, de grupos e das sociedades de países, regiões ou lugares, com diferenciações de intensidade e abrangência. De acordo ainda com Sacristán (2002, p. 71), dois debates importantes estão em curso, com projeções na educação: um relacionado à ideia de que a cultura globaliza-se, havendo então o risco de aniquilação - pela homogeneização cultural - das culturas menos "potentes"; o outro, no sentido de "[...] como conceber a cultura para responder à sensibilidade pelas diferenças culturais": algo necessário, mas implicando o

${ }^{1}$ LAPIERRE, J. W. Qu'est-ce qu'être citoyen? Paris: PUF, 2001. Comunicador e político canadense. 
perigo de "[...] cair no isolamento e nos particularismos que podem anular a universalidade do indivíduo nas sociedades complexas". Nesse contraponto de posições divergentes, emerge a necessidade de se olhar a cultura em perspectiva mais aberta, tendo como base a própria dinâmica da globalização, a qual, em sua estrutura produtiva, desencadeia o desenraizamento das populações, que levam consigo sua cultura para outros territórios e lugares e, com isso, surgem os conflitos socioculturais. Sob essa ótica, a cultura não pode mais ser visualizada como um legado ou uma tradição fixa, intocável, petrificada - mas como uma ambientação integrativa de pessoas e grupos humanos que, ao invés de manter fronteiras, reforça a coexistência de modos de vida e leituras de mundo. Como enfoca Sacristán (2002, p. 75), “a essência do existir de uma cultura como algo vivo é o fato de ser compartilhada, de englobar indivíduos [...]" e, nesse sentido, "[...] toda cultura pressupõe uma certa dinâmica de expansão ou de 'captação' de indivíduos".

Uma concepção aberta de cultura não nega os valores específicos, próprios, de cada cultura; não se trata de anular ou destruir culturas diferenciadas numa interculturalidade inviável e, sim, de inter-relacionar elementos, práticas, referências e aspirações comuns. Santos (2005, p. 135), colocando a questão dos "mitos da homogeneidade cultural" em contraposição aos contramitos da diversidade cultural, chama a atenção sobre um dos riscos a ser evitado, qual seja, o da "[...] aceitação incondicional da diversidade e [do] congelamento das diferenças [...]", com supervalorização das diferenças de etnia, de gênero, de classes, de cor, de crenças e do respeito aos que necessitam de cuidados especiais, à preservação do meio ambiente e a outros focos diferenciais, em detrimento das semelhanças e complementaridades das entidades culturais e, a mais, ignorando-se que as diferenças não são fixas, pois podem evoluir mediante processos de intercomunicações culturais, no tempo e no espaço.

As culturas, enquanto mundos com certas identidades socioculturais locais, regionais e globais, mudam pela movimentação de seus sujeitos - pessoas e grupos - que, ao deslocarem-se de lugar a lugar, intercambiam e socializam modos de falar e pensar, suas crenças, comportamentos e saberes práticos; essas dinâmicas interativas culturais geram hibridações muito mais desordenadas, complexas, pluridirecionais - não comportando coerência e delimitação previsíveis - do que confrontos de domínio ou relações de poder no contexto dos processos de globalização.

Sacristán (2002, p. 80) enfatiza o fenômeno da hibridação "[...] como um lugar real, como um espaço a desenvolver, como um ponto de vista para firmar atitudes de tolerância, como um modelo de entender a gênese da cultura que neutralize identidades excludentes"; e nesse sentido, segundo o mesmo autor, trata-se de “[...] admitir o intercâmbio cultural e de procurar fazer com que as culturas [...] não resistam a se misturar com as outras, amparando-se a diferença em seu direito. A possibilidade da construção de sociedades mais amplas incorpora, portanto, a permanência de diferenças compatibilizadas com interesses globalizados, em vista de benefícios partilhados pelos sujeitos. Então, sob essa perspectiva, a Educação é uma condição-chave para possibilitar as interações entre as diferenças socioculturais presentes no mundo globalizado e que impelem aos novos modos de vida, que implicam as questões ambientais.

\section{Educação ambiental e multiculturalismo}

A educação, enquanto promotora da cidadania democrática, tem que se orientar por finalidades multiculturais, que favoreçam aos sujeitos se reconhecerem em suas múltiplas e diferentes culturas, que estão em intercâmbio e os desvelam como sujeitos interculturais heterogêneos e semelhantes, em graus diversos. Para Sacristán (2002, p. 86), a consciência de "[...] saber-se seres interculturais ou mestiços [...] e admiti-lo [...] como algo enriquecedor é um traço de maturidade cultural". Nessa perspectiva, torna-se imprescindível a formação de uma cidadania solidária, no sentido de valorizar-se as várias instâncias culturais, desde a escola e as entidades comunitárias, como centros de tradição municipais, estaduais, regionais, sociedades e eventos que privilegiem o respeito à diversidade de culturas, em suas especificidades e complementaridades (SANTOS, 2005).

Na medida em que se forma a mentalidade de partilha intercultural nos sujeitos em escolarização e se dissemina em suas famílias e grupos sociais, tanto mais se mantém o potencial das sociedades criativas e construtivas - dado que não se "[...] elimina a diferença, mas a salvaguarda, considerando-a como um valor, enquanto não se choque com o padrão de referência comum" (SACRISTÁN, 2002, p. 91). O processo educativo escolar, democraticamente concebido e atuado, está comprometido com um foco ético quanto à dinâmica multicultural sob dois critérios: "[...] compreender e não exaltar ou enaltecer [...]" e [...] aproximar e não separar" (2002, p. 245). Daí que propostas ou programas educacionais, abertos ao multiculturalismo, devam incorporar uma depuração histórica dos mitos das 
culturas superiores, desenvolvendo uma justa concepção das culturas de pertencimento e experiência dos sujeitos, de modo a superar-se confrontos e exclusões, bem como reconstruir a dignidade das pessoas, pelo reconhecimento de suas identidades próprias; e a de grupos - como os ciganos $-\mathrm{e}$ até de povos que tenham sido discriminados, estigmatizados ou quase anulados (SACRISTÁN, 2002).

Uma das dimensões educativas que pode contribuir efetivamente com o enfoque sociomulticultural é a Educação Ambiental - em sua finalidade comprometida com uma Ética da Responsabilidade voltada à sustentabilidade da vida, em sentido amplo, envolvendo valores relacionados aos direitos transgeracionais, como solidariedade, justiça, liberdade de participação e expressão, tolerância etc. Esses direitos tiveram reafirmação na Conferência Mundial de Direitos Humanos das Nações Unidas, em Viena (1993)². Afirma-se, nessa conexão, a responsabilidade dos Estados pela proteção e promoção das identidades étnicas, culturais, linguísticas e religiosas (BRASIL, 2000, p. 37). Essa orientação da EA vincula-se a uma visão sociocultural da realidade ambiente, ou seja, focando meio ambiente para além de uma conotação simplesmente naturalista; assim, os objetivos da EA abrem-se ao campo das interações socioculturais com o meio biofísico, considerando toda sua constante dinâmica de mudanças e evolução. As modificações resultantes das relações entre sociedade e natureza podem ser ou não sustentáveis sob o ponto de vista da sociobiodiversidade, por sua vez diretamente relacionada com a multiculturalidade. Tais imbricações e implicações são intrínsecas aos modos de vida e leituras de mundo e, por consequência, têm de ser trabalhadas pela EA também multiculturalmente, no compromisso da educação escolar para com a qualidade de vida das sociedades humanas, tanto em suas diferenças quanto complementaridades. Nessa perspectiva, está implicada uma educação para a cidadania socioambiental que deve ter, como um dos pressupostos básicos, o desenvolvimento dos sujeitos-cidadãos em valores que promovam a coexistência de dinâmicas integrativas culturais, na medida em que a realidade envolve várias culturas num mesmo espaço e tempo e que nem sempre coexistem pacificamente e dificultam uma gestão ambiental de sociedade sustentável.

Viver a unidade na diversidade é um dos princípios fundamentais da cidadania socioambiental multicultural, tendo-se por base uma nova visão da Terra - como uma única comunidade. Isso significa, para cada um como para todos, ser cidadão de um mundo sem fronteiras, com um sentimento de pertença ao planeta Terra e à humanidade, a partir de modos de vida sustentáveis locais. Nessa linha de orientação, há necessidade de uma educação crítica comprometida com o processo de construção de relações sociais democráticas, pelas quais os sujeitos-alunos situem-se em suas próprias identidades e, nesse contexto, participem do desenvolvimento de uma cultura de direitos humanos e de diálogo entre culturas, em vista da convivência e sobrevivência num mundo intercultural, aceitando o " $[. .$. diferente como diferente, não como desigual ou inferior [...]” (KNECHTEL, 2005, p. 50).

Uma sociedade intercultural funda-se na compreensão de que os humanos são interdependentes e o bem-viver entre grupos e indivíduos dá-se mediante gestões solidárias e cooperativas, para além das práticas competitivas, pró-lucro e, pois, da concentração de riquezas. Porquanto, a diversidade cultural é sociopolítica como suporte da biodiversidade (LEFF, 2006) e, daí, constitutiva de condições mais equitativas da qualidade de vida em cada lugar - consequentemente, em nível planetário. A Educação Ambiental deve ter como finalidade intrínseca a formação de sujeitos eticamente responsáveis e preparados frente às questões socioculturais e ambientais, sob a perspectiva de decisões e ações ambientalmente mais adequadas, socioambientalmente justas, economicamente viáveis e culturalmente respeitosas das diferenças. Nesse sentido, a Educação Ambiental sob o foco multicultural, enquanto prática social ampla (formal ou não), constitui processo básico da formação de uma consciência político-cultural referenciada, crítica e autocrítica, numa dada comunidade, em torno da conquista de direitos e da responsabilização em termos de deveres pela dignidade de vida e pelo bem-estar de todos. Há, portanto, urgência de uma formação de educadores ambientais com enfoque multicultural para a sustentabilidade da vida com qualidade, envolvendo uma pedagogia crítica na linha da democracia solidária, includente e emancipadora, que corrobore a formação de sujeitos-cidadãos capazes de se comprometer com a realidade, refletindo e agindo em prol de um mundo mais humanizado (FREIRE, 1979). Essa orientação formadora vai “[...] além da aquisição de informações, sensibilização, explicação causal de fenômenos e mudança

\footnotetext{
${ }^{2}$ O Brasil foi signatário da Declaração dessa Conferência. A Declaração Universal dos Direitos Humanos, pela ONU, é de 1948, aprovada em 1966, mas que passou a vigorar só em 1976. <www.pge.sp.gov.br/centrodeestudos/ bibliotecavirtual/instrumentos/viena.htm>. Acesso em: 02/05/2008.
} 
de comportamento. É práxis, problematização e atuação na realidade [...]" (LOUREIRO, 2006, p. 132). Cabe, assim, aos formadores de educadores trabalhar com estes a capacitação a uma leitura compreensivo-interpretativa de mundo, fundada cientificamente e historicamente focada em cada contexto sociocultural (FREIRE, 1979).

\section{Formação de educadores e multiculturalismo}

Em vista da complexidade do mundo hodierno, faz-se necessário pensar a realidade multidimensionalmente; no entanto, a estrutura da organização social contemporânea, de orientação neoliberal, tem gerado uma apreensão unidirecional dos processos econômicos, políticos, culturais e educacionais - com isso, negando a pluralidade de ideias e culturas, de modos de existir específicos de comunidades e povos; assim, resultam favorecidos os mecanismos culturais de automatização de ser e agir, individual e coletivamente, com consequências limitadoras de decisões e ações criteriosas e criativas.

Morin (2007) afirma que na formação escolar ampla, inclusive universitária, são separados os objetos de estudo de seus contextos, bem como as disciplinas umas das outras, segundo uma lógica que leva os sujeitos a apreenderem a realidade de forma fragmentada e desconexa. Nessa linha, “[...] os espíritos tornam-se cegos a inter-retroações e à causalidade em circuito; consideram [...] os fenômenos vivos e sociais a partir de uma causalidade linear e de uma concepção mecanicista-determinista que vale unicamente para as máquinas" (MORIN, 2007, p. 18). Aí se torna inviável pensar uma realidade multicultural, em vista da valorização da pluralidade de mesclas em novas culturas, já que prevalece um pensamento etnocêntrico gerador de atitudes fechadas à emergência de identidades múltiplas, no sentido da relação unidade-diversidade, ou da hibridação cultural (SACRISTÁN, 2002). Nessa direção, pode-se questionar: como deverá ser a formação dos educadores ambientais sob o enfoque multicultural?

No contexto das práticas sociais, há que se considerar a possibilidade de outros direcionamentos teórico-metodológicos que valorizem a riqueza do diálogo cultural. Assim, na educação escolar, entendida como espaço social de múltiplas experiências, convivem a singularidade e a diversidade dos modos de vida e isso implica olhar os educadores e sua formação sob outras óticas que considerem: a) o multiculturalismo no contexto planetário, sob o foco das relações locais-globais; b) a democracia cognitiva como mentalidade aberta à sociobiodiversidade, gerando o sentido da mudança de pensamento e de atitude; c) a pedagogia da hibridação, como elemento orientador do trabalho docente; e d) a dialogicidade como abertura intercultural multirreferenciada. O conhecimento válido, segundo Morin (2001; 2007), precisa ser referido ao contexto das inter-relações socioculturais e ambientais, nas quais se desenvolve a história e a identidade de todos e de cada sujeito. Assim, a consciência do que é vivido só tem sentido passando pelos processos de apreensão, compreensão e apropriação dos contextos locais e mundiais objetiva e subjetivamente construídos nas inter-relações causais, como ponto onde se situa o multiculturalismo enquanto condição ou modo de vida contemporâneo. Nesse sentido, é importante que os educadores e os educadores dos educadores apreendam $\mathrm{e}$ aprendam o sentido da planetaridade - um dos sete saberes, segundo Morin (2000), necessários à educação no futuro.

Aprender a planetaridade implica compreender, nela, a multiculturalidade. Nessa direção, planetaridade e multiculturalidade contêm as características da mundialização econômica, cultural, social e política; essa última, compreendida contextualmente como tomada de decisão ética e responsável para com os modos de ser e viver cotidianos das localidades e comunidades, das mais conhecidas às mais remotas. Conforme Morin (2004, p. 37), “[...] a submissão impede de pensar; [...] é um modo mecânico onde não há mais iniciativa [...]" e, onde não há iniciativa, não haverá sentido de se buscar viver em democracia. A democracia implica agir consciente e responsavelmente nos espaços de vida, implica entender que, no contexto da mundialização, a vivência multicultural deve ser possível também no universo das ideias. Há grupos culturais descendentes de diferentes grupos étnicos que têm suas ideias, seu modo de pensar, de refletir, de agir e de criar a realidade que são excluídos ou negados pelas ideologias dominantes porque sua vivência e experiências não estão cientificamente sistematizadas.

Há, no vasto-pequeno mundo de hoje, uma elite científica burocratizada que pensa e produz ideias para manter determinados processos político-culturais, tentando inibir, ou até aniquilar, a participação de outras correntes de pensamento, de outros grupos ou etnias, de modos de vida não enquadrados nos padrões das elites economicamente privilegiadas. Essa forma de entender e conduzir a gestão do espaço mundial faz com que se viva uma pseudodemocracia, restritiva à participação cidadã de todos. A ciência, como forma sistemática de pensar a vida e a coletividade 
por meio de seus preceitos e encaminhamentos, precisa ser uma ciência cidadã (SANTOS, 2005), de modo que os sujeitos não sejam privados dela e, com isso, privados de participar do processo de construção do mundo, a partir de seus modos próprios de pensar e refletir. Nessa direção, em uma democracia cognitiva, conhecimentos e competências para conhecer precisam ser compartilhados (PENA-VEGA et al., 2003), apreendidos num processo cooperativo e de respeito pela sociobiodiversidade, em perspectiva efetivamente sustentável. Essa preocupação exige que se eduque o educador ambiental multicultural para entender o sentido dos valores que estão na base dos processos de aprender e conhecer, ou seja, na construção do saber e do viver de cada sujeito, em sua singularidade identitária e de coletividade.

Sacristán (2002) e Morin (2001) contribuem ao entendimento de que a condição globalizada ou mundializada, na qual se vive a realidade social hoje, exige um enfoque diferente dos processos de ensinar e aprender - da educação básica ao ensino superior. E essa mudança de enfoque será marcada não só pela forma de se construir os currículos, mas também pelo modo de conduzir a gestão dos mesmos - o que implica atitude de abertura frente ao entendimento de um mundo multirreferenciado, no qual ordem e desordem, organização e interação convivem e são complementares, como lógicas estruturantes da realidade. Esse entendimento implica pensar uma pedagogia da hibridação - entendida como espaço de coexistência de lógicas complementares na compreensão e explicação da realidade -, uma pedagogia na qual o trabalho docente esteja pautado no diálogo entre as ciências e outros saberes, na problematização e na análise multirreferenciada do real. Para tanto, é fundamental a consciência de que essa condição global de vida exige outra perspectiva pedagógica

[...] a partir da complexidade dos esquemas que são necessários para reorganizar nossos saberes especializados, os quais nos incapacitam para a compreensão da realidade que nos afeta, para saber acerca das responsabilidades que nos incumbem e para participar como cidadãos em uma sociedade cujos destinos são decididos em âmbitos nem sempre fáceis de identificar (SACRISTÁN, 2002, p. 96).
Uma pedagogia da hibridação com influências no trabalho docente - enquanto práxis político-pedagógica - volta-se aos aspectos do currículo que, segundo Morin (2000; 2007) e Morin e Kern (2001), ainda precisam ser pensados e concretizados como elementos indissociáveis da formação dos sujeitos-cidadãos, quais sejam: a formação do pensamento em rede, como construção de redes de saberes; o conhecimento dos outros e de si mesmo - de outras culturas e da própria identidade cultural como aspecto integrador e formador de uma consciência da interculturalidade multirreferenciada; a condição e a compreensão humanas, perpassadas de interrogações da incerteza; a era planetária e a ética, esta como condição sine qua non na formação do cidadão hodierno em tempo e espaços que se intercomunicam e são interdependentes. Estes aspectos, coorganizadores de currículos e constituintes de uma outra pedagogia, alicerçam a construção de aprendizagens voltadas a uma visão complexa, interdisciplinar e dialógica do mundo, em vista de sua transformação mais humanizadora e solidária (FREIRE, 1980), refletindo-se na formação de uma democracia cognitivamente responsável e aberta, condição esta que não pode ser negada na formação dos educadores ambientais, para atuarem em processos educativos ambientalmente interculturais na contemporaneidade.

\section{A interdisciplinaridade como prática pedagógica na formação dos educadores ambientais com enfoque multicultural}

Nesse contexto, de uma pedagogia da hibridação na formação de educadores voltada a outros caminhos teórico-metodológicos valorizantes do diálogo cultural, é que a interdisciplinaridade aparece como uma prática pedagógica aberta, dialógica e reflexiva - vinculada à prática social, na busca da aproximação dos saberes que consideram, sob diversos olhares, o intercâmbio cultural.

Sob esse olhar, a perspectiva interdisciplinar constitui uma característica essencial do processo formativo do educador, apresentando-se como um paradigma emergente ${ }^{3}$, em busca de um novo contexto do conhecimento, que não seja dualista, que privilegie a totalidade e a complexidade

\footnotetext{
${ }^{3}$ Conforme Santos (2002), esse novo paradigma pressupõe que não faz mais sentido a separação entre as ciências naturais e as ciências sociais, assim como há a necessidade de superação da dicotomia entre o conhecimento científico e o conhecimento vulgar (senso comum). Esse movimento abre-se a uma nova ordem científica, que não nega, mas busca a articulação entre ciências naturais e sociais e que considera, ademais, que todo conhecimento é local, total, autoconhecimento e multidimensional.
} 
do mundo real e que irrompa em dinâmicas construtoras de novos sentidos sobre a sociedade, a natureza e a cultura, como uma nova racionalidade que contemple o socioambiental de forma que os saberes possam ser inter-relacionados e articulados pelo próprio aspecto cultural, possibilitando a promoção de uma consciência da interculturalidade multirreferenciada.

A esse respeito, Floriani (2004), articulando novas estratégias cognitivas para se pensar as novas epistemologias socioambientais, caracteriza o novo contexto do conhecimento, recolocando alguns problemas, tais como: cada disciplina social, por não pensar o entendimento sobre a natureza, centrando-se em sua própria autonomia, em torno de objetos específicos, torna-se cada vez mais fragmentada; a necessidade de pensar uma reforma de pensamento pode desencadear a criação de outras disciplinas científicas; por ser a relação entre natureza e sociedade ampla, a questão ambiental deve redefinir os espaços de suas inter-relações por meio das ciências, da cultura e da política, buscando novos espaços de ressignificação de natureza e sociedade; deve-se, entretanto, questionar se a especialização nas ciências seja simplesmente negativa.

Sob a ótica dos problemas apontados, o novo contexto do conhecimento depara-se com um desafio epistêmico e metodológico, que é problematizar uma ciência disciplinar e fragmentária, redutora da complexidade do real. Por questionamentos problematizadores, reforça-se o pensar sobre uma pedagogia da hibridação que esteja apoiada na articulação e no diálogo constante entre as ciências e outros saberes, buscando-se "[...] reorientar o conhecimento para (re)aprender a unidade da realidade e para solucionar os complexos problemas gerados pela homogeneização forçada que induz a racionalidade econômico-tecnológica dominante" (LEFF, 2002, p. 170).

Para tal, considera-se que a interdisciplinaridade, orientada por finalidades multiculturais, propicia uma abertura dialógica e uma superação da linearidade e da artificialização, tanto no processo de produção do conhecimento como do ensino, bem como para superar-se o distanciamento de ambos em relação à realidade; nessa perspectiva faz-se possível, a partir de uma prática interdisciplinar, efetivar a intenção de articular as diversas áreas do saber, para uma melhor compreensão multicultural das relações entre sociedade e natureza.
A esse propósito, a prática interdisciplinar, como prática pedagógica, pode iniciar-se pela superação do dualismo entre pesquisa teórica e pesquisa prática, no sentido da "pesquisa orientada"4, assim intitulada por Japiassu (1976) ao adiantar que a perspectiva interdisciplinar instaura a pesquisa ao mesmo tempo teórica e prática; possibilita a relação de identificação entre o vivido e o estudado, desde que o vivido resulte da inter-relação de múltiplas experiências; permite a abertura de novos campos do conhecimento e conduz a novas descobertas; reconstitui a unidade dos objetos que a fragmentação dos métodos separou, permitindo aos pesquisadores a análise total e o diálogo entre as disciplinas; e busca a superação da dicotomia entre pesquisa e ensino, já que a pesquisa é também uma das formas de ensino e de aprendizagem e, por isto, faz-se necessária uma metodologia adequada para a pesquisa interdisciplinar (FAZENDA, 1992).

No curso dessa reconstrução está a Educação Ambiental, que - como processo necessário à formação de uma nova consciência cognitivo-democrática, pautada na prática interdisciplinar - possibilita integrar diversos saberes multiculturais, históricos, socioantropológicos e outros, todavia, neles incluído o saber popular, que se constrói ao mesmo tempo em que constrói o mundo. Sob esse enfoque, tem-se um dos postulados da interdisciplinaridade, dado que as áreas de conhecimento têm seus próprios limites, mas, em articulação com outras, podem levar o entendimento do mundo muito além daquele alcançado por uma disciplina de forma isolada.

A interdisciplinaridade, no âmbito da formação do educador ambiental multicultural, aparece como uma das saídas possíveis no bojo do debate político-sociopedagógico contemporâneo. Nesse foco, o grande desafio ainda está na tomada de consciência sobre o sentido do ser humano no mundo e não apenas na (re)organização metódica do conhecimento. Dessa forma, cabe aos seres humanos a compreensão de que estão no mundo, pensam e agem sobre esse mundo, afirmando-se como sujeitos interculturais heterogêneos e semelhantes, em graus distintos (FREIRE, 2007).

Diante do exposto, torna-se importante a reflexão em vista de uma práxis pedagógica interdisciplinar que possibilite ao educador conhecer-se em suas variadas formas de pensar e agir na busca de uma formação ambiental multicultural, como agente de transformação do mundo.

\footnotetext{
${ }^{4}$ Esse termo significa que a pesquisa é induzida pelo terreno sobre o qual é situada e vai além da simples aplicação do saber adquirido, para poder ter função crítica de um saber e um caráter inovador nas pesquisas científicas (JAPIASSU, 1976).
} 


\section{A universidade e a formação em educação ambi- ental sob o enfoque multicultural}

A universidade, como instituição de formação de educação técnica e superior, tem o papel essencial de assumir a responsabilidade no processo de produção de novos conhecimentos e de incorporação das atuais dimensões científicas e tecnoculturais à pesquisa e à formação profissional. Nesse sentido, dada a necessidade de enfrentamento dos problemas socioambientais hodiernos, torna-se pertinente propiciar aos educadores a pesquisa, a análise e a reflexão sobre a realidade em diversas abrangências conceituais sobre natureza, biodiversidade, historicidade, complexidade, sustentabilidade, multi e interculturalidade, reorientando o fazer profissional na linha de uma educação ambiental sob o enfoque multicultural.

Como instituição social, a universidade expressa a história de uma determinada sociedade, absorvendo, criando e exprimindo ideias, práticas e atividades acadêmicas para compreender e enfrentar hoje as necessidades urgentes em torno da sustentabilidade socioambiental, com vistas à melhoria das condições de vida, já precárias entre milhões de seres humanos e que comprometem o futuro planetário. Portanto, a elaboração e difusão de conhecimentos, saberes e práticas socioambientais são emergenciais nos âmbitos universitários.

Sob tal perspectiva, o saber socioambiental e, nesse contexto, o saber multicultural, são dimensões a serem internalizadas nos estudos acadêmicos. Nesse sentido, concorda-se com Leff (2001, p.30):

$\mathrm{Na}$ verdade, o saber ambiental ficou excluído num processo de extermínio dos saberes "não-científicos" (saberes errantes, ciganos, nômades), [onde se incluem os saberes culturais populares] no campo de concentração das externalidades do sistema econômico, social e político, bem como o científico-tecnológico dominante.

Os pesquisadores do ensino superior precisam inquirir e conhecer a própria história da sociedade e da ciência moderna para cumprir sua tarefa de produzir conhecimento com o reconhecimento das identidades histórico-culturais e socioambientais locais, regionais e nacionais e, então, trabalhar na perspectiva do respeito das diferenças socioambientais e multiculturais e não só transmitir cultura para treinar indivíduos a fim de que sejam produtivos para o mercado.
Sob esse foco, a instituição universitária tem hoje papéis determinantes para sua própria existência, enquanto entidade criativa, crítica e reflexiva, valorizando a dimensão socioambiental relacionada à questão multicultural e, nessa direção, impedindo o pensamento fragmentado e o bloqueio de setores e âmbitos diferenciados, emergentes ou evanescentes. Para tanto, a participação docente e discente é essencial, tanto no plano da produção material quanto no da produção intelectual.

Assiste-se ao esvaziamento e à redução do papel da universidade que, ao lidar com a constituição e a construção de saberes, cria um ensino superior distante da realidade atual. Do que se precisa é enfatizar a formação de profissionais pesquisadores, técnicos e dirigentes críticos, criativos e reflexivos, que enfrentem as contradições da realidade, as novas tecnologias e a complexidade que aí está, a fim de que sejam assegurados empregos e estágios aos estudantes, como também financiamentos para pesquisa, de acordo com os interesses e necessidades da sociedade contemporânea, privilegiando-se uma educação humanizadora em todas suas dimensões e garantindo a homens e mulheres a dignidade histórica de pessoas, fazendo-se mais humanos no mundo (FREIRE, 2007).

Daí poder afirmar-se que a universidade é uma instituição de pesquisa científica que deve favorecer a produção de conhecimento e a inovação tecnológica, bem como a formação de profissionais não apenas voltada às demandas do mercado capitalista, mas ao seu próprio desenvolvimento.

No entanto, a universidade enquanto produtora da ciência cedeu ao pensamento moderno, em cujo contexto todo esforço deu-se no sentido de conhecer o mundo para o enfrentamento das transformações das riquezas naturais em bens e serviços à disposição da sociedade global. Nesse sentido, o ensino universitário ficou dividido e fragmentado, quase que resultando numa renúncia ao saber totalizado. Essa renúncia não cabe mais hodiernamente no ensino e nem na pesquisa, que se têm contentado com instrumentalizar indivíduos para determinadas finalidades, "involucrando-os" em conhecimentos científicos disciplinares.

Destarte, a universidade moderna encontra-se em constante crise. Santos (1997, p.190) identifica-a como crise de hegemonia, de legitimidade e institucional, constituindo-se em afloramentos da crise do paradigma que sustenta a instituição universitária, mediante as racionalidades da modernidade, que são de base cartesiana, com função instrumental e reducionista. 
Nessa crise de paradigmas, as questões socioambientais e multiculturais, por conta da globalização, estão associadas a uma crise de conhecimento e de falta de respeito às diferenças socioculturais. Tais questões, por sua vez, problematizam a ciência moderna, que não dá mais conta de compreender a complexidade do real, as emergências da contemporaneidade, como os problemas socioambientais e, nesse bojo, o multiculturalismo. A universidade vive forte tensão entre as incertezas e os conflitos gerados por esses questionamentos, na urgência evidente de buscar a superação do paradigma mecanicista dominante na ciência moderna; isto põe a necessidade de se refletir sobre a relação entre os sistemas de pensamento e os desafios socioambientais e culturais.

Santos (1997; 2002), embora não considere que a universidade esteja preparada para assumir estes desafios de mudanças globais e organizacionais, acredita na possibilidade de que vivemos em um momento de transição paradigmática, ou seja, de transformação. O autor pauta-se no entendimento de que essa transição, da ciência moderna para a ciência pós-moderna, pode conduzir à reflexão sobre outro modelo de universidade, em que os processos de investigação, de ensino e de extensão propiciem a participação e a valorização da cultura das comunidades, pois, compartilhando também do pensamento de Leff (2001), a universidade deve ser um ponto privilegiado de encontro entre saberes e culturas. Compreende-se que estas questões representam fontes iniciais de produção do conhecimento sobre o respeito nos diferentes meios ambientes culturais e às diferenças multiculturais de etnia, de classes, de cor, de gênero, de sexo, de crenças, as necessidades de inclusão, de respeito aos que necessitam de cuidados especiais, enfim, dos problemas que agora estão sendo trazidos ao interior das escolas, quando antes estavam envoltas em obscuridade e sem nenhuma preocupação (KNECHTEL, 2005).

Continua a mesma autora, é necessário que o pessoal universitário - professor, pesquisador, estudante - identifique diferenças socioculturais, de modo a auxiliar na construção de alternativas de práticas educativas socioambientais integradas à cultura (KNECHTEL, 2005). Diante disso, "a política da universidade deve combinar o máximo de compromisso social", como bem considerado por Buarque apud SANTOS (1997, p. 209).

Considera-se que os conhecimentos científico, tecnológico e artístico gerado na universidade não são únicos. Há outras formas de conhecimento que surgem da prática de pensar e agir de inúmeros segmentos sociais ao longo de gerações que, por não serem caracterizadas como científicas, são desprovidas de legitimidade institucional. Essas práticas estão sendo resgatadas como uma atividade orgânica com a maioria da população (SANTOS, 1997).

A crise do conhecimento científico exige um novo papel da universidade, a qual é convocada a construir uma racionalidade que possibilite a transformação de paradigmas científicos tradicionais e a promoção de novos conhecimentos e de integração de diferentes saberes socioculturais, com a participação da sociedade.

Em vista de tal exigência, necessita-se problematizar a própria organização do pensamento e da instituição universitária sobre a necessidade de constante abertura ante questões e problemas contemporâneos. A esse propósito, Morin (2002, p.22) põe a importância de se pensar a reforma universitária como reforma de pensamento, no sentido de formar cidadãos capazes de enfrentar os problemas do seu tempo: "Assim, não se pode transformar só a instituição se as mentes não forem também transformadas".

Por sua vez, essa reforma implica uma articulação disciplinar que permita integrar as ciências naturais e as ciências sociais, sob um olhar complexo - o que convoca a universidade a superar-se para encontrar um caminho em que o pensamento complexo possa ser capaz de integrar, distinguir, unir, contextualizar e globalizar. E esse caminho é a busca de uma postura interdisciplinar.

Assim, há a necessidade de um pensamento e de pesquisas que reconheçam os fenômenos multidimensionais presentes na realidade, que são relacionais e conflituosos concomitantemente; que privilegiem a diferença e a alteridade e que compreendam a integração das partes em um todo, pelo reconhecimento do todo nas partes.

Dessa forma, o esgotamento do paradigma dominante que se tem vivenciado, tanto no desenvolvimento da ciência quanto na organização social, evidencia a necessidade de pensar a realidade, a partir do princípio da totalidade, de tal forma que sejam (re)construídas novas formas de organizar a vida em sociedade.

O ensino superior, considerado espaço de luta, criação, resistência, encontros e desencontros, precisa lançar-se aos desafios da complexidade do mundo, incorporando a dimensão socioambiental conectada com o multi e o intercultural como campos de coexistência. Para tal, necessita-se de um arranjo interdisciplinar das atividades de ensino nas universidades - o que, de certa maneira, "[...] exige a superação da estrutura departamental obsoleta, estabelecida por políticas educacionais autoritárias já historicamente 
superadas" (TOZONI-REIS, 2001, p. 46), em busca de um compromisso sustentável da instituição superior.

Diante desse cenário, a universidade, como centro de ciência, deve considerar a responsabilidade social e acadêmica enquanto valores relevantes na construção e reconstrução de um conhecimento que contemple a complexidade do real e, nesse contexto, a dimensão socioambiental frente às diferenças culturais, ampliando a visão de mundo dos profissionais. Mas como a universidade se posicionará diante da necessidade de trabalhar com uma educação socioambiental numa linha de multiculturalismo? Como as Instituições de Ensino Superior podem incorporar a Educação Ambiental numa perspectiva de multiculturalidade?

Urge considerar a importância da inserção dessa dimensão na produção do conhecimento na universidade, para encontrar subsídios, bem como critérios para o ensino e a pesquisa, fundamentando novos caminhos da formação dos profissionais educadores ambientais, que valorizem os diferentes elementos culturais das sociedades.

\section{A formação em Educação Ambiental sob o enfoque multicultural: trajetórias e reflexões na universidade}

Cabe agora apresentar uma rápida incursão histórica de como a Educação Ambiental vem se inserindo no ensino superior. Alguns pressupostos norteiam essa reflexão:

[...] formação ambiental é pertinente para compreender a transformação da realidade causada pela problemática do desenvolvimento. A formação implica um processo mais orgânico e reflexivo de reorganização do saber e da sociedade na construção de novas capacidades para compreender e intervir na transformação do mundo (LEFF, 2001, p. 254).

[...] Na história de sua cultura, o ser humano atinge o ontem, reconhece o hoje, descobre o amanhã ao se tornar um profissional pesquisador (KNECHTEL, 2005, p. 119).
A universidade deve problematizar as novas demandas sociais que implicam uma formação profissional direcionada ao campo da Educação Ambiental quanto à multiculturalidade, no rumo de novas tentativas de superar o paradigma neoliberal da globalização dominante e as fragilidades impostas na atualidade pelo sistema economicista.

A necessidade e a urgência de formação de educadores ambientais decorrem desde as recomendações da Conferência de Tiblisi (1977), na qual foram delineadas algumas diretrizes para a Educação Ambiental nos espaços universitários, tais como: romper com os modelos tradicionais de educação, ao aceitar a interdisciplinaridade para a produção de conhecimento sobre os problemas socioambientais; desenvolver materiais pedagógicos e estabelecer cooperações locais, nacionais e internacionais, bem como incluir no programa de formação de professores a Educação Ambiental; ajudar docentes dos centros de formação de professores na área de Educação Ambiental e facilitar, aos futuros professores, formação ambiental apropriada aos meios urbano ou rural (UNESCO, 1994). A esta orientação agrega-se, agora, a problemática de formação na visão da multiculturalidade, isto é, o respeito às diferenças culturais, motivando e criando práticas de identidade cultural, por meio da educação socioambiental multicultural.

Direcionados ao ensino superior, destacam-se os Seminários sobre "Universidade e Meio Ambiente" ocorridos no Brasil entre os anos 1986 e 1992. Uma análise avaliativa destes seminários, apontando embora uma sequência de aprofundamento na temática, evidencia que a relação da universidade com as questões ambientais dava-se, ainda recentemente, de forma limitada e os estudos multiculturais eram inexistentes.

Em decorrência desses primeiros seminários nacionais sobre Universidade e Meio Ambiente, aconteceu em 1990 o I Curso Latino-Americano de Especialização em Educação Ambiental, ofertado pelo PNUMA, IBAMA e Universidade Federal do Mato Grosso ${ }^{5}$. Assim, é a partir de 1990 que várias universidades, inspiradas nas recomendações e diretrizes traçadas nesses seminários, cunharam estratégias para incorporar a dimensão ambiental. Dentre as tentativas em romper com os paradigmas tradicionais que aprisionam o ensino superior, foram criadas disciplinas optativas e comissões interdepartamentais ou programas

\footnotetext{
${ }^{5}$ Curso criado em parceria com o Conselho Nacional de Desenvolvimento Científico e Tecnológico (CNPq) e com a Coordenação de Aperfeiçoamento de Pessoal de Nível Superior (CAPES). O curso foi reeditado até meados de 1994 e oferecido para funcionários do IBAMA, MEC e instituições universitárias.
} 
e cursos interdisciplinares - vinculados às reitorias para conseguir certa independência dos departamentos disciplinares - e também implementados cursos de pós-graduação lato e stricto sensu ${ }^{6}$ na área de educação e meio ambiente.

Com base nessa abertura, vale evidenciar que, com o ganho de aportes legais, teóricos e metodológicos, a década de 90 cooperou para a emergência de cursos de Pós-Graduação, desde Especialização até Mestrado e Doutorado. Entre muitos, destacam-se o curso de Mestrado e Doutorado em Educação Ambiental da Fundação Universidade Federal de Rio Grande (FURG-RS), o Programa Interdisciplinar do Doutorado em Meio Ambiente e Desenvolvimento e a Especialização em Educação, Meio Ambiente e Desenvolvimento da Universidade Federal do Paraná (UFPR), no qual vem se consolidando o processo interdisciplinar de pesquisa.

No âmbito desses novos espaços no ensino superior de discussão e reflexão quanto à Educação Ambiental, ressaltam-se igualmente os Encontros de Pesquisa em Educação Ambiental (EPEA), Encontros Nacionais da Associação Nacional de Pós-Graduação e Pesquisa em Ambiente e Sociedade (ANPPAS) e Encontros Nacionais da Associação Nacional de Pós-Graduação em Educação (ANPED). Assim, aos poucos a formação profissional dos educadores ambientais em cursos de pós-graduação vem destacando a pesquisa interdisciplinar e a intervenção ambiental. No entanto, observa-se que nas (re)construções teóricas e metodológicas de trabalhos de pesquisa em Educação Ambiental no Brasil não se tem privilegiado os estudos interculturais. Entretanto, é preciso avançar nos dois campos: educação ambiental e multiculturalismo - uma vez que coexistem na realidade, ou seja, práticas socioeducativas ambientais multiculturais se relacionam no contexto das sociedades. Os programas de graduação e pós-graduação (lato sensu e stricto sensu) deveriam estar produzindo um saber que valorizasse as relações sociedade, natureza, cultura e educação numa perspectiva crítico-reflexiva, com base no pensamento complexo e interdisciplinar.

Portanto, uma Educação Ambiental que estimule repensar as bases do conhecimento e o desenvolvimento da sociedade, nos cursos de graduação e pós-graduação, demanda iniciativas que devem ser instigadas nesses programas. Ressaltam-se aqui a necessidade de revisão de currículos e a inserção da dimensão ambiental ligada ao multicultural, como campos recíprocos no ensino superior, sob foco de um trabalho cooperativo interdisciplinar. Pois dessa maneira é que a Educação Ambiental poderá ir se concretizando no campo da produção de conhecimentos, nas práticas socioeducativas ambientais da universidade, bem como no cotidiano de escolas e comunidades.

\section{Perspectivas e avanços para uma abordagem multicultural}

Como já focado, o debate sobre o multiculturalismo vem gradativamente tomando espaço, nos últimos anos, no contexto de eventos e de estudos interculturais, com referência à relevância das identidades culturais nos diversos campos, inclusive no educacional; não havendo, porém, uma coligação entre Educação Ambiental e multiculturalismo como campos de coexistência.

A educação ambiental sob o enfoque multicultural é preocupação recente. Lentamente, vem-se pensando num processo de educação ambiental sob o enfoque multicultural, integrador de diferentes culturas e de respeito à diversidade sociocultural ambiental. No Brasil, os interesses por esses estudos têm se evidenciado só nas últimas décadas nos meios educacionais e de comunicação, em artigos, eventos e algumas teses, especialmente relacionados às práticas socioeducativas e discursos curriculares homogeneizadores e etnocêntricos, que dão ênfase a uma determinada cultura. No mundo globalizado, verifica-se um desrespeito às identidades socioculturais. Segundo o Programa das Nações Unidas para o Desenvolvimento (PNUD, 20047 apud CANDAU, 2008, p.46), as pessoas “[...] exigem mais justiça social, mais voz política, reconhecimento e respeito, pois desejam saber se viverão em uma sociedade diversificada ou numa sociedade conformada com uma única cultura dominante". Como vivem em contextos e modos muito diferentes, sofrem a discriminação e a marginalização quanto às oportunidades sociais, educacionais, econômicas e políticas.

Observam-se, historicamente, dificuldades para se lidar com a temática do preconceito e da discriminação racial e étnica. O Brasil, por muito tempo, não deu importância às

\footnotetext{
${ }^{6}$ Para efeito de esclarecimento, os cursos de lato sensu são cursos de especialização e aperfeiçoamento, enquanto os de stricto sensu incluem os cursos de mestrado e doutorado, com objetivos mais amplos e aprofundados da formação científica.

${ }^{7}$ PNUD - Programa das Nações Unidas para o Desenvolvimento. Relatório do desenvolvimento humano 2004: liberdade cultural num mundo diversificado. Lisboa: Mensagem, 2004.
} 
diferenças, dando ênfase à imagem de "país homogêneo" e de uma suposta "democracia racial". Isso repercutiu na escola, em que a discriminação racial e étnica evidencia-se ainda hoje por parte de professores, de alunos, do pessoal escolar, ainda que indireta ou inconscientemente, causando constrangimento, senão sofrimento, às pessoas expostas a esta situação, o que acarreta obstáculos ao processo de aprendizagem (BRASIL, 2000).

Em 1996, foram aprovados pelo Ministério da Educação e Cultura (MEC) os Parâmetros Curriculares Nacionais (PCN), que definiram como temas transversais: saúde, ética, orientação sexual, pluralidade cultural e meio ambiente.

A palavra transversalidade relaciona-se a temáticas que atravessam e perpassam os diferentes campos do conhecimento, fazendo articulação com as questões socioambientais. Trata-se de uma inovação curricular, pois, no âmbito da orientação a uma ética cidadã, para o aluno e professor, isso passou a ser definido como política do Estado no sistema educacional do país. Está, pois, fora de dúvida que a legislação brasileira reconheceu o papel fundamental da educação formal quanto à formação dos alunos e, igualmente, dos professores, não se restringindo apenas à instrução de saberes disciplinares.

$\mathrm{O}$ MEC propôs, com os $\mathrm{PCN}$, uma orientação à educação brasileira com o intuito de garantir o respeito às diversidades culturais, regionais, étnicas, religiosas e políticas, no sentido de construção da cidadania, de respeito ao meio ambiente, com o ideal crescente de igualdade de direitos entre os cidadãos, tendo por base os princípios democráticos. Isso sinaliza a necessidade de se considerar a dimensão intercultural no cotidiano da escola em todos os níveis de ensino. Todavia, não há ainda, também na escola, uma preocupação com a Educação Ambiental sob o enfoque multicultural.

A amplitude do tema exige a seleção de conteúdos e propostas práticas voltadas ao reconhecimento da realidade cultural e ambiental brasileira - compreendendo sua formação histórica, socioantropológica e a relação entre sociedade e natureza - cuja configuração, aos seus 509 anos de construção da nacionalidade, torna cada vez mais imperativo o respeito às identidades culturais, à preservação e conservação do meio ambiente e à vida digna dos seus habitantes.

A universidade, bem como a educação básica (ensino fundamental e médio) tem um papel crucial a desempenhar nesse processo, por meio de uma abordagem ambiental multicultural presente no currículo. Por quê?
- Sabe-se que o preconceito tem profundas raízes psicológicas, culturais, sociais, nem sempre abordadas no contexto do currículo e observadas no campo cultural quanto às identidades socioculturais (BRASIL, 2000).

- A escola é um espaço social, geográfico e cultural em que se dá a convivência entre estudantes de origens e níveis socioeconômicos diferentes, de costumes e crenças religiosas também diferentes daqueles que cada um conhece - com a visibilidade de mundo diverso daquele que compartilha em família (BRASIL, 2000).

- Outrossim, a educação formal é um dos lugares onde as regras do espaço público oportunizam o convívio democrático com a diferença, nem sempre proposto como uma prática socioeducativa que garanta o reconhecimento da realidade plural de um país como o Brasil, com diferenças culturais regionais marcantes.

A partir desses pressupostos socioculturalmente problematizantes, torna-se necessária uma proposta curricular que enfoque a formação de professores relativamente ao tema da pluralidade cultural, sob a perspectiva de uma educação ambiental sob o enfoque multicultural. Vale passar aqui um conceito propositivo de educação ambiental sob o enfoque multicultural, a fim de clarificar as práticas a serem desenvolvidas no decorrer das aulas e pesquisas, nos âmbitos formal e não-formal:

- a Educação ambiental sob o enfoque multicultural é um processo permanente no qual os indivíduos e a comunidade adquirem conhecimentos, valores, habilidades, experiências, reconhecimento de identidades culturais e ambientais e formam critérios de decisão, em vista de ações viáveis de resolução de problemas ambientais e socioculturais; portanto, essa perspectiva educacional preconiza a integração do ambiental com o multicultural, no sentido dos alunos e comunidade apreenderem as questões socioambientais e culturais, valorizando a diversidade e a coexistência das mesmas, enquanto princípio de sustentabilidade dos grupos étnicos diversificados dentro de uma sociedade.

\section{Considerações finais}

Diante da realidade brasileira, entende-se que as práticas de Educação Ambiental voltadas ao multiculturalismo podem contribuir significativamente para a construção de relações socioculturais democráticas, visando-se ao desenvolvimento de uma sociedade plural e integrada pelo compromisso para com os direitos e deveres da cidadania. 
Nesse sentido, as instituições formadoras de educadores devem assumir um grande desafio sob o aspecto da inovação teórico-metodológica dos currículos, desenvolvendo e alimentando uma nova proposta de vida em sociedade, humanizada e solidária tanto socioambientalmente quanto socioculturalmente. Daí que este estudo buscou relacionar a Educação Ambiental com o multiculturalismo, enfocando a necessidade da formação de profissionais nessa relação, para possibilitar a formação de sujeitos-alunos respeitosos na convivência com a realidade intercultural da sociedade globalizada.

Para tanto, há necessidade de se considerar, na formação de educadores ambientais, aspectos fundamentais como: a) a globalização, como fenômeno macrossocial contemporâneo multidimensional (econômico, social, político etc.) que afeta as sociedades em geral, tendo influência substantiva no processo da globalização cultural; a Educação Ambiental deve valorizar as racionalidades culturais na promoção da cidadania socioambiental; essa apreensão do multiculturalismo e da Educação Ambiental como campos de coexistência das racionalidades culturais possibilitará aos educadores atuarem criticamente na perspectiva da hibridação cultural; b) uma Educação Ambiental não orientada por uma visão multissociocultural crítica tende a reproduzir racionalidades culturais etnocêntricas, negando espaço a culturas socialmente marginalizadas, desconsiderando os direitos da identidade diferencial de cada cultura e opondo dificuldades ao intercâmbio e diálogo interculturais; c) a Educação Ambiental sob o enfoque multicultural, voltada ao desenvolvimento pessoal e social em conexão com o meio ambiente e a cultura, possibilitará aos sujeitos uma compreensão autônoma, crítica e criativa das realidades socioambientais, de seus problemas e soluções possíveis, sob a ótica da partilha solidária; d) o avanço da reflexão teórico-metodológica sobre a relação do multiculturalismo com a Educação Ambiental favorecerá a compreensão da complexidade da interculturalidade plurirreferenciada, na perspectiva de uma ciência cidadã, i.é, do conhecimento epistemicamente referenciado, eticamente comprometido com o respeito cooperativo pela sociobiodiversidade e tecnicamente sustentável; e) a construção de uma pedagogia da hibridação, alicerçada numa visão interdisciplinar e complexa de mundo, enquanto práxis política na formação dos educadores e dos educadores ambientais, permitirá que os docentes atuem nos processos educativos de forma cognitivamente democrática, solidária e eticamente responsável.

Esses aspectos salientados indicam elementos fundamentais a um avanço no campo da Educação Ambiental, em vista da formação de educadores ambientais. Nessa direção, a perspectiva delineada nessa pesquisa, coloca-se como aporte que pode subsidiar a atuação dos educadores e a forma de se pensar as propostas de Educação Ambiental em escolas e nas investigações voltadas ao aprofundamento das questões socioambientais.

\section{Referências}

BRASIL. Ministério da Educação. Parâmetros curriculares nacionais (1. ${ }^{\mathrm{a}}$ a $4 .^{\mathrm{a}}$ série): pluralidade cultural; orientação sexual. 2. ed. Rio de Janeiro: DP\&A, 2000.

BUARQUE, C. A aventura da Universidade. São Paulo: UNESP, 1994.

CANDAU, V. M. Direitos humanos, educação e interculturalidade: as tensões entre igualdade e diferença. Revista Brasileira de Educação, v. 13, n. 37, 2008.

FAZENDA, I. C. A. Integração e interdisciplinaridade no ensino brasileiro: efetividade ou ideologia. São Paulo: Edições Loyola, 1992.

FLORIANI, D. Conhecimento, meio ambiente e globalização. Curitiba: Juruá, 2004.
FREIRE, P. Educação e mudança. 14. ed. Rio de Janeiro: Paz e Terra, 1979.

Conscientização: teoria e prática da libertação: uma introdução ao pensamento de Paulo Freire. São Paulo: Moraes, 1980.

. Pedagogia da autonomia: saberes necessários à prática educativa. 35. ed. São Paulo: Paz e Terra, 2007.

JAPIASSU, H. Interdisciplinaridade e patologia do saber. Rio de Janeiro: Imago, 1976.

KNECHTEL, M. R. Multiculturalismo e processos educacionais. Curitiba: Ibpex, 2005.

LEFF. E. Saber ambiental: sustentabilidade, racionalidade, complexidade, poder. Petrópolis: Vozes, 2001. 
Epistemologia ambiental. São Paulo: Cortez, 2002.

Racionalidade ambiental: a reapropriação social da natureza. Trad. de Luis Carlos Cabral. Rio de Janeiro: Civilização Brasileira, 2006.

LOUREIRO, C. F. B. Problematizando conceitos: contribuição à práxis em educação ambiental. In: LOUREIRO, C. F. B.; LAYRARGUES, P. P.; CASTRO, R. C. (Orgs.). Pensamento complexo, dialética e educação ambiental. São Paulo: Cortez, p. 104-161, 2006.

MORIN, E. Os sete saberes necessários à educação do futuro. 2. ed. São Paulo: Cortez; Brasília: UNESCO, 2000.

. A cabeça bem-feita: repensar a reforma, reformar o pensamento. 5. ed. Rio de Janeiro: Bertrand Brasil, 2001.

Saberes globais e saberes locais: o olhar transdisciplinar. 5. ed. Rio de Janeiro: Garamond, 2004.

Educação e complexidade: os sete saberes e outros ensaios. 4. ed. São Paulo: Cortez, 2007.

; KERN, A. B. Terra-Pátria. 2. ed. Lisboa: Instituto Piaget, 2001.

; MOIGNE, J. L. A inteligência da complexidade. 2.

ed. São Paulo: Peirópolis, 2000.
PENA-VEGA, A.; ALMEIDA, C. R. S.; PETRAGLIA, I. Edgar Morin: ética, cultura e educação. 2. ed. São Paulo: Cortez, 2003.

SACRISTÁN, J. G. Educar e conviver na cultura global: as exigências da cidadania. Trad. de Ernani Rosa. Porto Alegre: Artmed Editora S.A., 2002.

SANTOS, B. S. Pela mão de Alice: social e o político na pós-modernidade. São Paulo: Cortez, 1997.

Um discurso sobre as ciências. Porto: Edições Afrontamento, 2002.

SANTOS, M. E. V. M. dos. Que cidadania? Tomo II: Que educação? Para que cidadania? Em que escola? Lisboa: Edição Santos-Edu, 2005.

TOZONI- REIS, M. F. C. Educación ambiental: referencias teóricas en la enseñanza superior. Interface_Comunic, Saúde, Educ., v. 5, n. 9, p. 33-50, 2001.

UNESCO. Programa Internacional de Educación Ambiental. Estratégias para la formación del profesorado en educación ambiental. Vasco: CENEAN, libros de la Catarara, n. 25, 1994.

Recebido em março de 2010.

Aceito em julho de 2010 .

Publicado em dezembro de 2010. 